\title{
Interaction of Chlamydia trachomatis serovar E with male genital tract epithelium results in secretion of proinflammatory cytokines
}

Correspondence

Adrian Eley

adrian.eley@uaeu.ac.ae

Received 20 February 2007

Accepted 16 April 2007

\author{
Najwa Al-Mously and Adrian Eley†
}

Henry Wellcome Laboratories for Medical Research, Unit of Infection and Immunity, School of Medicine, University of Sheffield, Beech Hill Road, Sheffield S10 2RX, UK

\section{INTRODUCTION}

Chlamydia trachomatis causes the most prevalent sexually transmitted bacterial infection as it affects more than 90 million people annually worldwide (Norman, 2002). In males, C. trachomatis may cause different urogenital infections, ranging from lower to upper genital tract diseases. This bacterium has been found to be responsible for more than $50 \%$ of all organisms causing nongonococcal urethritis (Bakare et al., 2002; Falk et al., 2004), and around $50 \%$ of all cases of chronic prostatitis caused by infectious agents (Skerk et al., 2004). Moreover, a potential association between $C$. trachomatis infection and benign prostatic hypertrophy $(\mathrm{BPH})$ has been established (Corradi et al., 1996; Toth et al., 2000). A high prevalence of asymptomatic persistent $C$. trachomatis infection among infertile couples has also been reported

tPresent address: Department of Medical Microbiology, Faculty of Medicine and Health Sciences, United Arab Emirates University, PO Box 17666, Al Ain, United Arab Emirates.

Abbreviations: $\mathrm{BPH}$, benign prostatic hypertrophy; $\mathrm{EB}$, elementary body; IFU, inclusion forming unit; IL, interleukin; RB, reticulate body; TNF $\alpha$, tumour necrosis factor alpha.
(Idahl et al., 2004), and although the effect of this bacterium on male fertility is still controversial, possibilities include an effect on semen parameters or sperm function (Hosseinzadeh et al., 2001; Segnini et al., 2003; Idahl et al., 2004).

C. trachomatis is a Gram-negative bacterium that lives as an obligate intracellular parasite within the host cell. This bacterium has a unique developmental cycle in which the organism is present in two main forms, the elementary body (EB), which is the extracellular infectious form, and the reticulate body (RB), which is the intracellular metabolically active form that divides by binary fission. In certain conditions, a third form can be seen, which is larger than the size of a RB and is called atypical or aberrant. These atypical forms can result in a long-term relationship with infected host cells leading to persistent chlamydial infection (reviewed in Hogan et al., 2004).

Epithelial cells in the human genital tract, as epithelial cells elsewhere, secrete different cytokines in response to disease conditions, such as infections. However, some of these epithelial surfaces do secrete certain cytokines in normal conditions. It has been suggested that epithelial cells can act 
as an early alarm system by creating a network connected to local and to distant cells in the host for the production of the inflammatory response (Eckmann et al., 1995; Pate et al., 2001). In vitro as well as in vivo studies involving female genital tract epithelium have demonstrated a different inflammatory response according to the site of infection and the pathogen involved (Fichorova et al., 2001; Reddy et al., 2004). C. trachomatis infection is known to cause secretion of a range of cytokines from epithelial cells, such as interleukin $1 \alpha$ (IL- $1 \alpha$ ), IL-6, IL- 8 and others. This was shown by in vitro studies performed on ectocervical and endocervical cell lines, in addition to cells from a non-genital origin (Rasmussen et al., 1997; DessusBabus et al., 2002; Hanada et al., 2003).

Little is known about the pathogenesis of $C$. trachomatis in the male genital tract as most of the in vitro studies on genital chlamydial infection have been carried out using cell lines derived from females. In the present study, we established C. trachomatis serovar E infection in epithelial cells derived from the male urogenital tract, including immortalized normal (transformed) human urethral epithelial cells (THUEC) and immortalized normal adult male prostate epithelial cells (PNT2). We then compared the ability of $C$. trachomatis to grow in both cell lines with the ability to grow in cervical cells (HeLa) by counting the inclusion forming units (IFU) recovered from the three infected cell lines in McCoy cells. In addition, we investigated cytokine release by these cell lines, in comparison with HeLa cells, in response to C. trachomatis infection.

\section{METHODS}

Cell lines. The normal male THUEC were a kind gift of Professor M. Apicella (Department of Microbiology, University of Iowa, Iowa City, IA, USA). These cells were grown, maintained and passaged as described by Harvey et al. (2002), in brief, cell cultures were maintained in fetal calf serum (FCS)-free prostate epithelial growth medium (PrEGM) (Cambrex Bioscience). During passaging, $0.5 \%$ trypsin/5.3 mM EDTA was used for lifting cells for $5 \mathrm{~min}$ at room temperature, then after removal of enzymes, cells were kept at $37{ }^{\circ} \mathrm{C}$ for $5 \mathrm{~min}$. Cells were then suspended in $5 \%$ FCS-PrEGM, centrifuged at $1100 \mathrm{~g}$ and suspended in the required volume of FCS-free PrEGM prior to seeding.

The PNT2 cell line was obtained from the European Collection of Cell Cultures (ECACC, Salisbury, UK) and was maintained in RPMI 1640 with glutamine and $10 \%$ FCS (Gibco-BRL).

McCoy cells, and HeLa 229 cells (ECACC, Salisbury, UK) were maintained in minimum essential medium (Cambrex Bioscience) supplemented with $10 \%$ FCS. All cell lines were maintained according to the supplier's instructions and all were regularly tested for the absence of Mycoplasma species.

C. trachomatis. Serovar E, which is reported to be the most frequently encountered serovar causing C. trachomatis infections (Geisler et al., 2006), was isolated from a clinical sample obtained from the Department of Genitourinary Medicine, Royal Hallamshire Hospital, Sheffield, UK. Confirmation of the genotype was conducted by sequence analysis according to the method of Dean et al. (2000).
The serovar was grown in flasks and EBs harvested, purified and kept at $-80{ }^{\circ} \mathrm{C}$ as described previously (Taraktchoglou et al., 2001).

Visualization and quantification of chlamydia by direct immunofluorescence. Cells were grown on coverslips in 24-well tissue culture plates, infected with chlamydiae, incubated for $24-48 \mathrm{~h}$ at $37{ }^{\circ} \mathrm{C}$, and then fixed with methanol for $5 \mathrm{~min}$. Coverslips were then stained with fluorescein isothiocyanate-conjugated $\mathrm{mAb}$ specific for the Chlamydia major outer-membrane protein (MOMP) (Trinity Biotech). The number of IFUs was counted using fluorescence microscopy at a $\times 400$ magnification. The mean number of inclusions per field was determined by counting inclusions in 20 different fields. The number of IFU ml ${ }^{-1}$ was then calculated. EBs were counted by making serial dilutions and taking a known amount of each dilution into a Teflon-coated slide well, followed by air drying, fixing with methanol and then staining as mentioned above. The mean number of EBs was counted at $\times 100$ magnification in different fields in one well and the number of EBs $\mathrm{ml}^{-1}$ was calculated.

Growth curve experiment. The growth curve was analysed for the three cell types following the method described by Lyons et al. (2005) but with slight modifications. Confluent growth of THUEC, PNT2 and HeLa cells $\left(5 \times 10^{5}\right)$ in 24 -well tissue culture plates was inoculated with equal inocula of purified EBs at a m.o.i. of $25: 1$. After centrifugation at $2000 \mathrm{~g}$ for $1 \mathrm{~h}$ at $4{ }^{\circ} \mathrm{C}$, all cells were washed; fresh medium without cycloheximide was added and incubated at $37^{\circ} \mathrm{C}$. Cycloheximide was omitted to represent a more natural environment in which there is unrestricted growth of host cells as described in Hanada et al. (2003). After 24, 48, 72, and 96 h post-infection, cells were scraped off and collected together with supernatants in duplicate. Samples were then sonicated and kept at $-20{ }^{\circ} \mathrm{C}$ until cultured on McCoy cells seeded on coverslips in 24-well tissue culture plates, for the purpose of counting IFUs using direct immunofluorescence staining.

Determination of cytokine levels in culture supernatants by ELISA. Culture supernatants were collected from THUEC, PNT2 and HeLa cell cultures infected with C. trachomatis (m.o.i. 5:1) at 1, 3, and 7 days post-infection. Non-infected cultures of the same three cell types were used as controls. Supernatants were collected and kept at $-20{ }^{\circ} \mathrm{C}$. Three independent experiments were carried out for THUEC, PNT2 and HeLa cells. The cytokine concentrations were measured by using commercial ELISA kits (Quantikine; R\&D systems) for the detection of IL- $1 \alpha$, IL- 6 , IL- 8 , IL-10 and tumour necrosis factor alpha (TNF $\alpha)$. All tests were carried out strictly according to the manufacturer's instructions.

Statistical analysis. The results from the growth curve experiments and the cytokine experiments were analysed by one-way analysis of variance using Instat (Graph Pad Software). A $P$ value of $<0.05$ was considered significant.

\section{RESULTS AND DISCUSSION}

\section{Susceptibility of THUEC and PNT2 cells to $C$. trachomatis infection}

Epithelial cells from the female genital tract, such as HeLa cells, have been extensively used by researchers to study different aspects of $C$. trachomatis infection, in addition to non-epithelial cells such as macrophages (Swanson et al., 1998; Taraktchoglou et al., 2001; Kuo et al., 2002). In this study we investigated the interaction of this bacterium with its natural site of infection in the male, the genital tract 
epithelium, in comparison with HeLa cells. We demonstrated the ability of this bacterium to infect THUEC and PNT2 cells. Inclusions could be seen $24-48 \mathrm{~h}$ post-infection and the increase in infective dose led to a concomitant increase in the number of inclusions (data not shown).

\section{Growth curve}

Chlamydial growth in THUEC and PNT2 cells was investigated and compared to growth in HeLa cells (Fig. 1). The yield of IFU in McCoy cells from samples taken $24 \mathrm{~h}$ post-infection was much less than the yield from $48 \mathrm{~h}$ post-infection samples for the three cell lines. There was a sharp increase in the number of IFU $48 \mathrm{~h}$ postinfection in all cell types with the highest being in HeLa cells. There was also a significant difference in the number of IFU at $48 \mathrm{~h}$ post-infection between both THUEC $(P<0.001)$, PNT2 cells $(P<0.05)$ and HeLa cells. Thereafter, the number of IFU started decreasing for all cell lines. Interestingly, there was a significant difference in the yield of IFU between THUEC and PNT2 cells at 48 and $96 \mathrm{~h}$ post-infection $(P<0.001)$.

The initial experiments that were evaluated using fluorescence microscopy demonstrated that both THUEC and PNT2 cells were susceptible to infection with $C$. trachomatis to a similar extent to that seen with HeLa and McCoy cells. However, in the light of our results from the growth curve experiments, it was obvious that the yield of chlamydial EBs from HeLa cells was significantly higher than from THUEC $(P<0.001)$ and PNT2 $(P<0.05)$ cells at $48 \mathrm{~h}$ post-infection. Also, chlamydial growth is better supported in PNT2 cells than in THUEC, and this was reflected by the significant difference in the yield of IFUs between these cells $48 \mathrm{~h}$ post-infection $(P<0.001)$.

\section{Cytokine levels in culture supernatants}

Infection with $C$. trachomatis has been shown to induce an acute host response, which is primarily initiated in infected

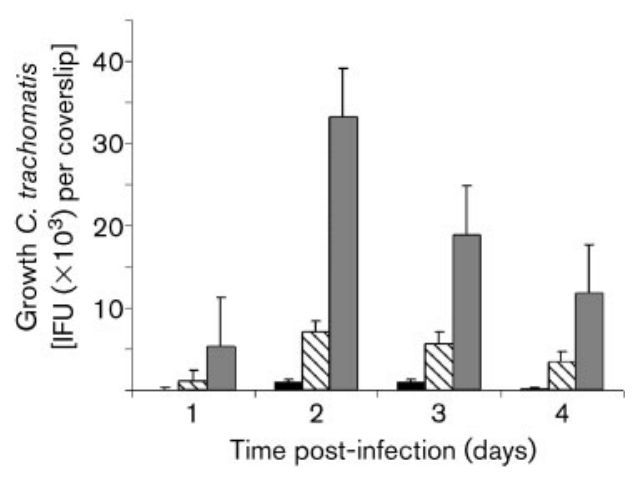

Fig. 1. Growth of C. trachomatis (m.o.i. $25: 1$ ) in THUEC (black bars), PNT2 (hatched bars), and HeLa (grey bars) cells. Values are the mean number of IFU+SEM from three independent experiments. epithelial cells both in vivo and in vitro (Magee et al., 1992; Rasmussen et al., 1997). These infected cells may release inflammatory cytokines that are essential for the development of an adaptive immune response, which if persistently elicited may lead to chronic inflammation-associated tissue damage and scarring, leading eventually to the ultimate cause of disease sequelae (Stephens, 2003). However, different epithelial cells may react in different ways to C. trachomatis infection, and different serovars may induce different levels of cytokines in response to infection (Rasmussen et al., 1997; Dessus-Babus et al., 2002). In the latter two studies they used mainly cell lines representing the female genital tract and other non-genital epithelial cells. Reports on cytokine release by epithelial cells from the human male genital tract after infection with $C$. trachomatis in vitro are still lacking. In our study, we demonstrated that THUEC and PNT2 cells have the ability to produce certain cytokines in response to serovar $\mathrm{E}$ that were different in magnitude and timescale from cytokines released by HeLa cells. Our clinical isolate of C. trachomatis was chosen as we have used it in several published studies of its pathogenicity to human sperm (Hosseinzadeh et al., 2001, 2003; Eley et al., 2005). We analysed the supernatants from the three cell types for five different cytokines starting from 1 day to 7 days post-infection. We started the detection at day 1 post-infection because chlamydiae typically need $48-72 \mathrm{~h}$ to complete their growth cycle, unlike rapidly dividing bacteria (Rasmussen et al., 1997).

\section{IL-1 in culture supernatants}

THUEC, PNT2 and HeLa cells were challenged with chlamydiae and there was an increase in the levels of certain cytokines produced in the cells in a time-dependent fashion. Cytokine levels in unchallenged cells were also detectable in the three cell types. Fig. 2 shows the levels of IL- $1 \alpha$ released from the three cell lines with and without chlamydial challenge. IL- $1 \alpha$ secretion in THUEC started earlier than in HeLa, and both cell types had reached their highest levels at day 7 post-infection. There was a significant difference between the levels on day 1 and day 7 in both THUEC and HeLa cells $(P<0.05$ and $P<0.001$, respectively). IL- $1 \alpha$ levels in PNT2 remained low over the 7 day period of the experiment. The levels of IL- $1 \alpha$ detected in THUEC and HeLa cells were observed to be significantly higher than levels in PNT2 cells at day $7(P<0.0001)$.

IL- $1 \alpha$ is an important mediator of inflammation that helps to accelerate the specific immune response (Sigal, 2005). It has been reported that IL- $1 \alpha$ is important in regulating host defences against C. trachomatis (Magee et al., 1992; Rasmussen et al., 1997; Buchholz \& Stephens, 2006). In our experiments, THUEC were the first cells to release IL- $1 \alpha$ and high levels were maintained throughout the 7 day infection period. PNT2 and HeLa cells behaved differently, and only after 7 days post-infection were levels in HeLa close to those in THUEC. This early release of IL- $1 \alpha$ by THUEC may be explained by the fact that in this cell line 


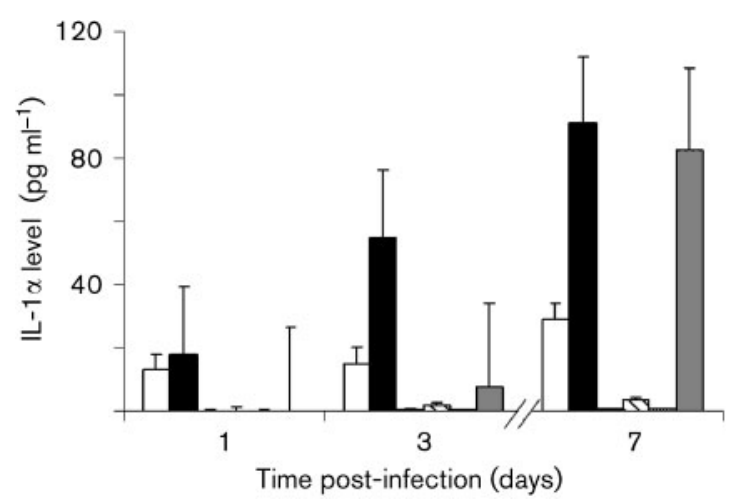

Fig. 2. Levels of IL-1 $\alpha$ following chlamydial infection of THUEC [control (white bars), infected (black bars)], PNT2 cells [control (bars with horizontal lines), infected (hatched bars)] and HeLa cells [control (bars with vertical lines), infected (grey bars)]. Cell culture supernatants were collected after 1, 3, and 7 days of incubation from each cell type from an uninfected control, and from cells with chlamydial infection (m.o.i. $5: 1$ ). Values are the means + SEM from three independent experiments.

IL- $1 \alpha$ is secreted by viable cells early in the infection in the absence of cell lysis. With HeLa cells (and to a lesser extent PNT2 cells) the delayed release of this cytokine was possibly due to lysed cells, which would be found in larger numbers 3-7 days post-infection. Published work has shown a correlation between vaginal IL- $1 \alpha$ levels and the development of symptoms of infection with Neisseria gonorrhoeae in vivo and in vitro (Ramsey et al., 1995). However, a study by Pate et al. (2001), which investigated cytokine levels in urethral swabs, did not find a significant difference in the level of IL- $1 \beta$ between uninfected and infected male patients with $C$. trachomatis. We found that there were higher levels of IL- $1 \alpha$ released from THUEC than from PNT2 cells, and that could simply be due to differences between these epithelial cells or it may be related to the fact that $C$. trachomatis infection in the prostate is usually asymptomatic, whereas infection of the urethra is often symptomatic (Weidner et al., 1991; Krause et al., 2003; Miller, 2006). Our results are similar to those reported in a study on infertile females infected with $C$. trachomatis (Reddy et al., 2004). In their study, they reported that the levels of IL-1 in cervical secretions were higher than levels in Fallopian tubes, which suggests an association between raised IL-1 levels and C. trachomatis infection in the lower genital tract.

\section{IL-6 in culture supernatants}

IL-6 is a cytokine that exerts different biological activities, one of which is the activation of B cells (Van Snick, 1990). It has been documented that IL-6 plays an important role in host defence against chlamydial infection, as well as other infections caused by different organisms (Magee et al.,
1992; Williams et al., 1998; Mokart et al., 2005; Ross et al., 2006).

IL-6 levels (Fig. 3) in the PNT2 cells were observed to be high after day 1 post-infection (222-fold more than in THUEC and 10-fold more than in HeLa cells) and remained high at day 7 . However, at day 7 post-infection, IL-6 levels in HeLa cells were higher than those in PNT2 cells. IL-6 production in THUEC was low even at day 7 post-infection. Interestingly, IL-6 may be involved in the immunopathogenesis of persistent chlamydial infection (Mpiga et al., 2006). Elevated IL-6 levels have been reported in cases of persistent $C$. trachomatis infection of the Fallopian tube, as well as in chronic latent Chlamydia pneumoniae infection in vivo (Li \& Liang, 2000; Ohsawa et al., 2001; Jitsuiki et al., 2006). Moreover, Hanada et al. (2003) investigated the release of IL-6 from chlamydiaeinfected fibroblast-like synovial cells over a 7 day period and reported an association between large amounts of IL- 6 released and persistent $C$. trachomatis infection in these cells. Our results with one cell line are in agreement with this association as we could observe the formation of abnormally large RBs in some inclusions in PNT2 cells but not with other cell lines tested. Furthermore, IL- 6 is one of the cytokines that has been suggested to be a marker for cases of male accessory gland infection and chronic pelvic pain syndrome (Orhan et al., 2001; Matalliotakis et al., 2002). Our in vitro findings if reproduced in vivo suggest that IL-6 could possibly be a marker for chlamydial prostatitis. The low levels of IL-6 from THUEC in response to chlamydial infection were similar to those levels from the same cell line when stimulated with $N$. gonorrhoeae (Harvey et al., 2002), although a higher baseline secretion of IL-6 was seen in our study, which may be due to technical differences in the assay. IL-6 levels in HeLa cells in our study were slightly higher than those reported by

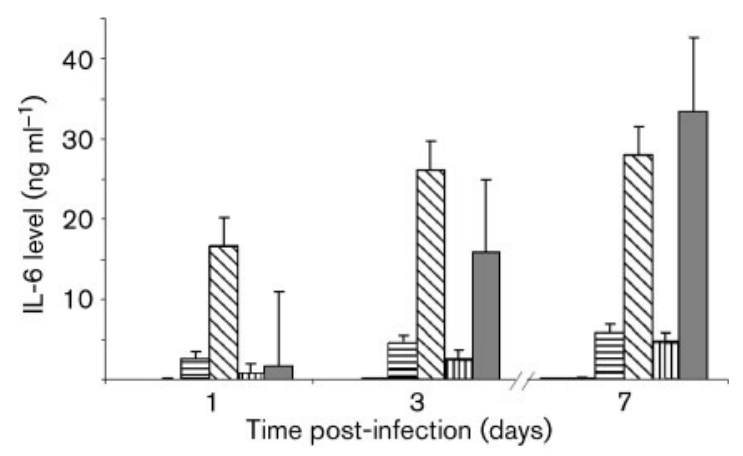

Fig. 3. Levels of IL-6 following chlamydial infection of THUEC [control (white bars), infected (black bars)], PNT2 cells [control (bars with horizontal lines), infected (hatched bars)] and HeLa cells [control (bars with vertical lines), infected (grey bars)]. Cell culture supernatants were collected after 1,3 and 7 days of incubation from each cell type from an uninfected control, and from cells with chlamydial infection (m.o.i. 5:1). Values are means + SEM from three independent experiments. 
Mpiga et al. (2006) when they infected HeLa cells with serovar L2. This difference could be explained by the different chlamydial serovar used as well as technical differences in the design of the experiment.

\section{IL-8 in culture supernatants}

IL-8 is a chemotactic factor that activates neutrophils, basophils and $\mathrm{T}$ cells during the inflammatory response (Mukaida et al., 1998). It has been reported that $C$. trachomatis can induce the production of IL-8 by infected cells during in vivo and in vitro infection (Kalinka et al., 2005; Buchholz \& Stephens, 2006; Mpiga et al., 2006). IL-8, similar to IL-6, may participate in the immunopathogenesis of chronic chlamydial infection (Dolgushin et al., 2004; Mpiga et al., 2006).

Fig. 4 shows IL-8 levels in THUEC, PNT2 and HeLa cells. IL-8 levels in PNT2 and HeLa cells were observed to be higher than levels in THUEC (at day 3, around eightfold and sixfold increases, respectively). However, at day 7 postinfection, IL-8 levels in HeLa cells were nearly threefold higher than in PNT2 cells.

In this study, we observed that chlamydial infection had triggered THUEC, PNT2 and HeLa cells to produce IL-8, and the levels in all cell types increased in a time-dependent manner. Similar levels of IL-8 produced in HeLa cells in response to $C$. trachomatis infection have been reported by Rasmussen et al. (1997); however, some workers have noticed a decrease in the release after $72 \mathrm{~h}$ post-infection (Yu et al., 2003). Interestingly, when $\mathrm{HeLa}$ cells were infected with $C$. trachomatis and were then co-cultured

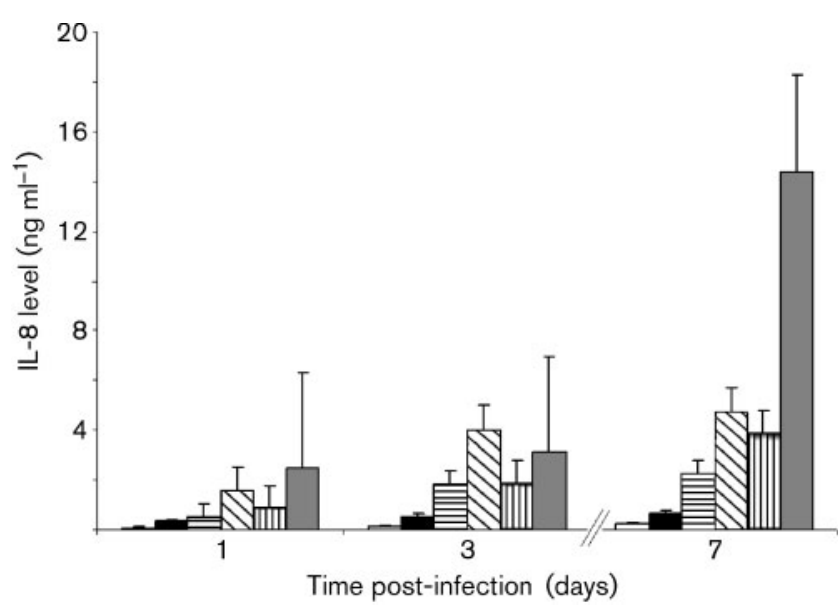

Fig. 4. Levels of IL-8 following chlamydial infection of THUEC [control (white bars), infected (black bars)], PNT2 cells [control (bars with horizontal lines), infected (hatched bars)] and HeLa cells [control (bars with vertical lines), infected (grey bars)]. Cell culture supernatants were collected after 1, 3 and 7 days of incubation from each cell type from an uninfected control, and from cells with chlamydial infection (m.o.i. 5:1). Values are means + SEM from three independent experiments. with THP-1 cells, the IL-8 response was much higher and sustained (Mpiga et al., 2006).

Elevated IL-8 is suggested to be a useful clinical tool to help diagnose male accessory gland infection (Matalliotakis et al., 2002). High IL-8 levels in prostatic tissues have been reported in chronic prostatitis (Hu et al., 1998). Herein, we report elevated levels of IL-8 in PNT2 cells in response to $C$. trachomatis infection in vitro. The presence of chlamydial antigen in prostatic tissues has been suggested to be one of the reasons leading to the development of $\mathrm{BPH}$ (Corradi et al., 1996; Toth et al., 2000), whilst others have suggested that increased IL-8 expression in senescent epithelial cells will lead to the development of BPH (Castro et al., 2004). A question as to whether there is any association between our observation of elevated IL-8 levels in prostate cells in vitro with the development of $\mathrm{BPH}$ in vivo still needs to be answered. In this study, we observed that the release of IL-8 was much higher in PNT2 cells than in THUEC. In a study on female patients infected with chlamydiae they observed that in the Fallopian tubes, the IL-8 levels were higher than those secreted in the cervical region (Reddy et al., 2004), which strengthens our belief that increased IL-8 levels are found in the upper genital tract. Our results showing a slight increase in IL-8 levels in THUEC following chlamydial infection are similar to the results of IL-8 released from the same cell line in response to $N$. gonorrhoeae infection (Harvey et al., 2002). Although Hang et al. (1998) have reported that IL-8 is constitutively produced from epithelial cells of all parts of the urinary tract, Pate et al. (2001) observed a significant increase in IL-8 levels in patients with chlamydial urethritis. However, Pate et al. (2001) did not measure IL-8 levels in the upper genital tract so that comparisons with our data cannot be made.

A study by Rasmussen et al. (1997) using a different group of epithelial cells including HeLa and primary endocervical cells infected with different chlamydial serovars, demonstrated that there are two mechanisms responsible for the release of IL- 8 , and these are the IL- $1 \alpha$-dependent and IL$1 \alpha$-independent mechanisms. A recent report by Buchholz \& Stephens (2006) has suggested that the early release of IL- 8 by infected cells (less than $48 \mathrm{~h}$ post-infection) is IL- $1 \alpha$ independent, and that the late release (between $48-72 \mathrm{~h}$ post-infection) is mediated by IL- $1 \alpha$ with the increase in cell lysis. Because of the nature of our experiments, we were unable to confirm these data.

\section{TNF $\alpha$ and IL-10 in culture supernatants}

TNF $\alpha$ and IL-10 levels in THUEC, PNT2 and HeLa cells (both challenged and unchallenged cells) were undetectable at the minimum detectable concentrations of the ELISA kits. According to the manufacturer, 0.5 and $3.9 \mathrm{pg} \mathrm{ml}^{-1}$ were the minimum detectable concentrations of TNF $\alpha$ and IL-10, respectively. As we were not able to detect IL-10 and $\mathrm{TNF} \alpha$ in our experiments it may suggest that chlamydialinduced IL- 6 and IL-8 release was TNF $\alpha$ independent. 
Undetectable levels of TNF $\alpha$ have been reported by other groups who conducted in vivo as well as in vitro studies on the immune response in $C$. trachomatis infection (Pate et al., 2001; Dessus-Babus et al., 2002; Hanada et al., 2003). Yu et al. (2003) have reported high levels of IL-10 from HeLa cells infected with C. trachomatis, but they used serovar $\mathrm{K}$ and their experimental protocol was quite different to that used in our study. It is important to note that we observed a moderate release of IL- 1 and IL- 6 with the three unchallenged cell types, and generally a substantial release for IL-8 in PNT2 cells, which most probably reflect methodological differences in our attempt to optimize cytokine release in challenged cells. More typically less cytokine is released in unchallenged cells in vitro, as has been reported by other groups using different cell lines, some of which were primary and others immortalized, in addition to in vivo studies (Rasmussen et al., 1997; Fichorova et al., 2001; Reddy et al., 2004).

In conclusion, the THUEC and PNT2 cell lines used in this study can support the invasion of $C$. trachomatis, and initiate a proinflammatory response to infection, which may play a key role in inflammation and the associated immune response in vivo. These immortalized cell lines are useful tools to explore further aspects of chlamydial pathogenesis in the male genital tract and it is important to use a physiologically relevant cell type to that invaded by the same bacterium during in vivo infection (Harvey et al., 2002). In our experiments, we confirm the suggestion that high levels of IL-6 (which are associated with aberrant EBs) could be a possible marker for chlamydial prostatitis. Although not as marked a change, we also suggest that higher IL-8 levels could be associated more with chlamydial infection of the prostate than the urethra. Two recent publications (Gatti et al., 2006; Mackern-Oberti et al., 2006) have shown in an in vitro rat model of Chlamydia muridarum infection that prostate cells not only constitutively express significant levels of TLR4 and CD14 mRNA but also upregulate a number of different proinflammatory cytokine genes. Although this was a rat model using a different chlamydial species, nevertheless, it would suggest a similar response by prostate cells to this type of infection. In our in vitro study, differential cytokine production by different male-derived epithelial cells if reproduced in vivo could help determine the site of chlamydial infection and help in the study of pathogenesis. Epithelial cells from the male genital tract also behaved differently in vitro in certain aspects of infection to cells from the female genital tract, which may possibly suggest a difference in inflammatory response in vivo and be related to a difference in sequelae of the disease. However, we realize that our findings are based on work with one serovar and that other serovars should be investigated for comparison. It should also be stressed that as in other studies, it is often difficult to relate in vitro findings to what might happen in vivo, and that in vivo there is also likely to be subject to subject variation in cytokine response. More studies, including the use of these male derived epithelial cells, in what is a currently neglected area are needed to understand possible differences in the pathogenesis of $C$. trachomatis in the male and female genital tracts.

\section{ACKNOWLEDGEMENTS}

We would like to thank Professor Michael Apicella from the University of Iowa for carefully reading the manuscript. We would also like to thank Margaret Lee and Ian Geary for technical assistance.

\section{REFERENCES}

Bakare, R. A., Oni, A. A., Umar, U. S., Okesola, A. O., Kehinde, A. O., Fayemiwo, S. A. \& Fasina, N. A. (2002). Non-gonococcal urethritis due to Chlamydia trachomatis: the Ibadan experience. Afr J Med Med Sci 31, 17-20.

Buchholz, K. R. \& Stephens, R. S. (2006). Activation of the host cell proinflammatory interleukin-8 response by Chlamydia trachomatis. Cell Microbiol 8, 1768-1779.

Castro, P., Xia, C., Gomez, L., Lamb, D. J. \& Ittmann, M. (2004). Interleukin-8 expression is increased in senescent prostatic epithelial cells and promotes the development of benign prostatic hyperplasia. Prostate 60, 153-159.

Corradi, G., Bucsek, M., Panovics, J., Verebelyi, A., Kardos, M., Kadar, A. \& Frang, D. (1996). Detection of Chlamydia trachomatis in the prostate by in-situ hybridization and by transmission electron microscopy. Int J Androl 19, 109-112.

Dean, D., Suchland, R. J. \& Stamm, W. E. (2000). Evidence for longterm cervical persistence of Chlamydia trachomatis by omp1 genotyping. J Infect Dis 182, 909-916.

Dessus-Babus, S., Darville, T. L., Cuozzo, F. P., Ferguson, K. \& Wyrick, P. B. (2002). Differences in innate immune responses (in vitro) to HeLa cells infected with nondisseminating serovar $\mathrm{E}$ and disseminating serovar L2 of Chlamydia trachomatis. Infect Immun 70, 3234-3248.

Dolgushin, I. I., Kurnosenko, I. V., Dolgushina, V. F., Ugai, I., Abramovskikh, O. S. \& Gol'tsfarb, V. M. (2004). Clinical and immunological aspects of cervicitis of chlamydial etiology. $\mathrm{Zh}$ Mikrobiol Epidemiol Immunobiol 3, 48-52 (in Russian).

Eckmann, L., Kagnoff, M. F. \& Fierer, J. (1995). Intestinal epithelial cells as watchdogs for the natural immune system. Trends Microbiol 3, 118-120.

Eley, A., Hosseinzadeh, S., Hakimi, H., Geary, I. \& Pacey, A. A. (2005). Apoptosis of ejaculated human spermatozoa is induced by coincubation with Chlamydia trachomatis lipopolysaccharide. Hum Reprod 20, 2601-2607.

Falk, L., Fredlund, H. \& Jensen, J. S. (2004). Symptomatic urethritis is more prevalent in men infected with Mycoplasma genitalium than with Chlamydia trachomatis. Sex Transm Infect 80, 289-293.

Fichorova, R. N., Desai, P. J., Gibson, F. C., III \& Genco, C. A. (2001). Distinct proinflammatory host responses to Neisseria gonorrhoeae infection in immortalized human cervical and vaginal epithelial cells. Infect Immun 69, 5840-5848.

Gatti, G., Rivero, V., Motrich, R. D. \& Maccioni, M. (2006). Prostate epithelial cells can act as early sensors of infection by up-regulating TLR4 expression and proinflammatory mediators upon LPS stimulation. J Leukoc Biol 79, 989-998.

Geisler, W. M., Suchland, R. J. \& Stamm, W. E. (2006). Association of Chlamydia trachomatis serovar Ia infection with black race in a 
sexually transmitted diseases clinic patient population in Birmingham, Alabama. Sex Transm Dis 33, 621-624.

Hanada, H., Ikeda-Dantsuji, Y., Naito, M. \& Nagayama, A. (2003). Infection of human fibroblast-like synovial cells with Chlamydia trachomatis results in persistent infection and interleukin-6 production. Microb Pathog 34, 57-63.

Hang, L., Wullt, B., Shen, Z., Karpman, D. \& Svanborg, C. (1998). Cytokine repertoire of epithelial cells lining the human urinary tract. $J$ Urol 159, 2185-2192.

Harvey, H. A., Post, D. M. \& Apicella, M. A. (2002). Immortalization of human urethral epithelial cells: a model for the study of the pathogenesis of and the inflammatory cytokine response to Neisseria gonorrhoeae infection. Infect Immun 70, 5808-5815.

Hogan, R. J., Mathews, S. A., Mukhopadhyay, S., Summersgill, J. T. \& Timms, P. (2004). Chlamydial persistence: beyond the biphasic paradigm. Infect Immun 72, 1843-1855.

Hosseinzadeh, S., Brewis, I. A., Eley, A. \& Pacey, A. A. (2001). Coincubation of human spermatozoa with Chlamydia trachomatis serovar E causes premature sperm death. Hum Reprod 16, 293-299.

Hosseinzadeh, S., Pacey, A. A. \& Eley, A. (2003). Chlamydia trachomatis-induced death of human spermatozoa is primarily caused by lipopolysaccharide. J Med Microbiol 52, 193-200.

Hu, F., Yu, P., Shu, M., Dai, G., Luo, Y. \& Zhou, A. (1998). Detection of interleukin-8 and nitric oxide in chronic prostatitis. Hunan Yi Ke Da Хие Хие Bao 23, 566-568 (in Chinese).

Idahl, A., Boman, J., Kumlin, U. \& Olofsson, J. I. (2004). Demonstration of Chlamydia trachomatis IgG antibodies in the male partner of the infertile couple is correlated with a reduced likelihood of achieving pregnancy. Hum Reprod 19, 1121-1126.

Jitsuiki, K., Yamane, K., Nakajima, M., Nakanishi, S., Tasaki, N., Watanabe, H., Kurihara, H. \& Kohno, N. (2006). Association of Chlamydia pneumoniae infection and carotid intima-media wall thickness in Japanese Americans. Circ J 70, 815-819.

Kalinka, J., Wasiela, M., Sobala, W. \& Brzezinska-Blaszczyk, E. (2005). Usefulness assessment of selected proinflammatory cytokines' level in cervico-vaginal fluid of pregnant women as an early marker of preterm delivery. Ginekol Pol 76, 704-712 (in Polish).

Krause, W., Bohring, C., Gueth, A., Horster, S., Krisp, A. \& Skrzypek, J. (2003). Cellular and biochemical markers in semen indicating male accessory gland inflammation. Andrologia 35, 279-282.

Kuo, C. C., Puolakkainen, M., Lin, T. M., Witte, M. \& Campbell, L. A. (2002). Mannose-receptor positive and negative mouse macrophages differ in their susceptibility to infection by Chlamydia species. Microb Pathog 32, 43-48.

Li, H. \& Liang, Z. (2000). Determination of tumor necrosis factor- $\alpha$ and interleukin- 6 levels of the tubal fluids in patients with infertility caused by infection of Chlamydia trachomatis. Zhonghua Fu Chan Ke Za Zhi 35, 411-412 (in Chinese).

Lyons, J. M., Ito, J. I., Jr, Pena, A. S. \& Morre, S. A. (2005). Differences in growth characteristics and elementary body associated cytotoxicity between Chlamydia trachomatis oculogenital serovars D and $\mathrm{H}$ and Chlamydia muridarum. J Clin Pathol 58, 397-401.

Mackern-Oberti, J. P., Maccioni, M., Cuffini, C., Gatti, G. \& Rivero, V. E. (2006). Susceptibility of prostate epithelial cells to Chlamydia muridarum infection and their role in innate immunity by recruitment of intracellular Toll-like receptors 4 and 2 and MyD88 to the inclusion. Infect Immun 74, 6973-6981.

Magee, D. M., Smith, J. G., Bleicker, C. A., Carter, C. J., Bonewald, L. F., Schachter, J. \& Williams, D. M. (1992). Chlamydia trachomatis pneumonia induces in vivo production of interleukin-1 and -6. Infect Immun 60, 1217-1220.
Matalliotakis, I., Arici, A., Goumenou, A., Koumantakis, G., Selam, B., Matalliotakis, G. \& Koumantakis, E. (2002). Distinct expression pattern of cytokines in semen of men with genital infection and oligoterato-asthenozoospermia. Am J Reprod Immunol 48, 170-175.

Miller, K. E. (2006). Diagnosis and treatment of Chlamydia trachomatis infection. Am Fam Physician 73, 1411-1416.

Mokart, D., Merlin, M., Sannini, A., Brun, J. P., Delpero, J. R., Houvenaeghel, G., Moutardier, V. \& Blache, J. L. (2005). Procalcitonin, interleukin 6 and systemic inflammatory response syndrome (SIRS): early markers of postoperative sepsis after major surgery. Br J Anaesth 94, 767-773.

Mpiga, P., Mansour, S., Morisset, R., Beaulieu, R. \& Ravaoarinoro, M. (2006). Sustained interleukin-6 and interleukin-8 expression following infection with Chlamydia trachomatis serovar L2 in a HeLa/THP1 cell co-culture model. Scand J Immunol 63, 199-207.

Mukaida, N., Harada, A. \& Matsushima, K. (1998). Interleukin-8 (IL8 ) and monocyte chemotactic and activating factor (MCAF/MCP-1), chemokines essentially involved in inflammatory and immune reactions. Cytokine Growth Factor Rev 9, 9-23.

Norman, J. (2002). Epidemiology of female genital Chlamydia trachomatis infections. Best Pract Res Clin Obstet Gynaecol 16, 775-787.

Ohsawa, I., Ohi, H., Endo, M., Fujita, T., Hidaka, M., Satomura, A. \& Yamaguchi, Y. (2001). A case of renal involvement in persistent immune activation caused by chlamydial salpingitis. Virchows Arch 438, 306-311.

Orhan, I., Onur, R., Ilhan, N. \& Ardicoglu, A. (2001). Seminal plasma cytokine levels in the diagnosis of chronic pelvic pain syndrome. Int $J$ Urol 8, 495-499.

Pate, M. S., Hedges, S. R., Sibley, D. A., Russell, M. W., Hook, E. W., III \& Mestecky, J. (2001). Urethral cytokine and immune responses in Chlamydia trachomatis-infected males. Infect Immun 69, 7178-7181.

Ramsey, K. H., Schneider, H., Cross, A. S., Boslego, J. W., Hoover, D. L., Staley, T. L., Kuschner, R. A. \& Deal, C. D. (1995). Inflammatory cytokines produced in response to experimental human gonorrhea. $J$ Infect Dis 172, 186-191.

Rasmussen, S. J., Eckmann, L., Quayle, A. J., Shen, L., Zhang, Y. X., Anderson, D. J., Fierer, J., Stephens, R. S. \& Kagnoff, M. F. (1997). Secretion of proinflammatory cytokines by epithelial cells in response to Chlamydia infection suggests a central role for epithelial cells in chlamydial pathogenesis. J Clin Invest 99, 77-87.

Reddy, B. S., Rastogi, S., Das, B., Salhan, S., Verma, S. \& Mittal, A. (2004). Cytokine expression pattern in the genital tract of Chlamydia trachomatis positive infertile women - implication for T-cell responses. Clin Exp Immunol 137, 552-558.

Ross, M. J., Fan, C., Ross, M. D., Chu, T. H., Shi, Y., Kaufman, L., Zhang, W., Klotman, M. E. \& Klotman, P. E. (2006). HIV-1 infection initiates an inflammatory cascade in human renal tubular epithelial cells. J Acquir Immune Defic Syndr 42, 1-11.

Segnini, A., Camejo, M. I. \& Proverbio, F. (2003). Chlamydia trachomatis and sperm lipid peroxidation in infertile men. Asian $J$ Androl 5, 47-49.

Sigal, L. H. (2005). Basic science for the clinician 27: Toll-like receptors and nucleotide oligomerization domains. J Clin Rheumatol 11, 176-179.

Skerk, V., Krhen, I., Schonwald, S., Cajic, V., Markovinovic, L., Roglic, S., Zekan, S., Andracevic, T. \& Krizic, V. (2004). The role of unusual pathogens in prostatitis syndrome. Int J Antimicrob Agents 24 (Suppl. 1), S53-S56.

Stephens, R. S. (2003). The cellular paradigm of chlamydial pathogenesis. Trends Microbiol 11, 44-51. 
Swanson, A. F., Ezekowitz, R. A., Lee, A. \& Kuo, C. C. (1998). Human mannose-binding protein inhibits infection of HeLa cells by Chlamydia trachomatis. Infect Immun 66, 1607-1612.

Taraktchoglou, M., Pacey, A. A., Turnbull, J. E. \& Eley, A. (2001). Infectivity of Chlamydia trachomatis serovar LGV but not $\mathrm{E}$ is dependent on host cell heparan sulfate. Infect Immun 69, 968-976.

Toth, M., Patton, D. L., Campbell, L. A., Carretta, E. I., Mouradian, J., Toth, A., Shevchuk, M., Baergen, R. \& Ledger, W. (2000). Detection of chlamydial antigenic material in ovarian, prostatic, ectopic pregnancy and semen samples of culture-negative subjects. Am J Reprod Immunol 43, 218-222.
Van Snick, J. (1990). Interleukin-6: an overview. Annu Rev Immunol 8, 253-278.

Weidner, W., Jantos, C., Schiefer, H. G., Haidl, G. \& Friedrich, H. J. (1991). Semen parameters in men with and without proven chronic prostatitis. Arch Androl 26, 173-183.

Williams, D. M., Grubbs, B. G., Darville, T., Kelly, K. \& Rank, R. G. (1998). A role for interleukin-6 in host defense against murine Chlamydia trachomatis infection. Infect Immun 66, 4564-4567.

Yu, J. L., Yu, P. \& Li, L. X. (2003). HeLa cells secrete interleukin-8 and interleukin-10 response to Chlamydia trachomatis entry. Hunan Yi Ke Da Xие Xие Bao 28, 174-176 (in Chinese). 